without its shape being destroyed, or no change whatever in the specimen. The field of non-destructive testing should cover all tests except those in which the specimen is destroyed.

Engineers are usually obliged to attach most importance to those properties which are determined from tests in which the specimen is destroyed. This means that the actual material which goes into service is not tested. As advances take place in engineering design, and materials are required to operate under increasingly severe conditions, it is becoming essential to know that the material put into service has the properties quoted from tests on specimens taken from it. Non-destructive tests should therefore be developed which will give this information, and the means of establishing such tests will come by three lines of study : how those properties determined by non-destructive tests vary with the constitution and structure of materials; how these properties can be used to identify changes in constitution and structure; and how to relate changes in constitution and structure to those properties which are determined by destructive tests.

\section{APPLICATIONS OF ULTRASONICS CONFERENCE IN MARSEILLES}

$\mathrm{T}$ HERE have been a number of conferences on various aspects of ultrasonics during the past few years, and that held in Marseilles during May 23-28, under the auspices of the Centre National de Recherches Scientifiques, was devoted to applied ultrasonics, though some papers on fundamental aspects were also read. The conference was subdivided into four sections comprising physical, chemical and medicobiological applications and transducers. Most papers fell into the first and third divisions. Prof. F. Canac (66 rue St. Sebastian, Marseille), the organizer of the conference, expects to publish in a book all the papers presented, and they may also appear as a special volume of Acustica.

The scientific part of the meeting opened with an account of the pioneer work of Langevin and Florisson in the use of ultrasonics for underwater detection, recalled by Prof. F. Canac, and then Prof. A. Giacomini presented statistics of the different types of applications during the past twenty years. About fifty sectional lectures and papers were read, of which it is only possible here to mention those which involve recent applications in industry and the like.

R. G. Busnel and M. Degrois showed an interesting film of the actions produced in a liquid under pressure when small cavitation bubbles appear in the liquid and the familiar geyser rises from the free surface. At higher pressures the latter disappears, particularly when the pressure is diminishing, and the cavitation nuclei coalesce leaving a flat free surface. No explanation was offered for these experiments, and as only one frequency was tried it is not possible to determine whether resonant vibrations of the cavity bubbles are concerned.

Prof. E. Meyer showed some interesting experiments with ultrasonics in a large box, imitating on a small scale the distribution of the sound amplitude throughout an auditorium due to a steady audible source. It was possible, by varying the form of protuberances applied to a wall and by having the other walls either hard or absorbent, to study the diffusive properties of the box for the ultrasonics. Dr. E. G. Richardson gave an account of the incidence of ultrasonics in recent aeronautical research, dealing in particular with the high-frequency output of jet engines and relaxations in substitute vapours used in supersonic wind-tunnels. The former was also the theme of an investigation by Mlle. M. Merle, who used small jets in the laboratory.

L. Bergmann described an apparatus for quickly giving warning of the presence of an explosive mixture in a room, by the use of an ultrasonic interferometer, while C. Florisson and R. Esche and collaborators described apparatus for coagulating and generating, respectively, aerosols of fine dispersion; these are of importance in chemical industry and the practice of medicine. In the same field V. Gavreau described the development of ultrasonic whistles which can be applied to-among other things-the coagulation of smoke.

A considerable number of papers occupied the medical and biological section, mainly emanating from Germany, where this type of application is much developed. Applications of ultrasonies in this field ranged from the treatment of nervous diseases and cancer to promoting the germination of wheat and killing of bacteria. To some of these a specific effect of frequency (or of wave-length) was attributed ; but in many applications, apart from the concentration of energy to be obtained, it seems that vibrations over quite a gamut of frequency can be effectively employed (this is also true of the formation of emulsions, as M. Degrois and his colleagues showed).

After thirty years of experience of ultrasonics in applied biology, it is not yet definite how far the effects are thermal and how far mechanical, but Dr. J. Stetler gave an interesting lecture on this problem, describing some careful experiments in which he sought to distinguish these two effects by using first continuous waves and then reiterated pulses of different lengths. In the fourth section, it is only possible to cite a lecture by C. F. Brockelsby, in which he gave many data for the development of magneto-striction generators of high power.

\section{INSTITUTE FOR SCIENTIFIC RESEARCH IN CENTRAL AFRICA}

\section{REPORT FOR 1952}

$T$ HE fifth annual report of the Institute for Scientific Researeh in Central Africa, Leopoldville, Belgian Congo, covering the year 1952 has recently been published*. Besides the administrative reports, among which that of the director, L. van den Berghe, gives a summary of the scientific work of the Institute during the year, it includes V. G. Dethier's paper on the biting response of tsetse flies, a bibliography of Plasmodium berghei by $\mathrm{I}$. $\mathrm{H}$. Vincke and M. Lips, an account by the director of the laboratories of the Institute at the Scientific Research Centre at Kivu, Lwiro, and a long account of the medical mycology of the Belgian Congo by R. Vanbreuseghem. A bibliography of papers published during the year by members of the Institute's staff or associated investigators is amplified by abstracts of the papers.

* Institut pour la Recherche Scientiflque en Afrique Centrale (I.R.S.A.C.) : Cinquieme Rapport Annuel. Pp. 377. (From the Institute's Offices in Brussels, 1955.) 
Among investigations in progress noted by the director in his report are an entomological inventory of the different natural regions as a prelude to a study of their fauna and a study of the entomological fauna of the remains of the primary forests still existing in Ruanda-Urundi; investigations on the cycle of trypanosomes; and studies of climatic and technical problems in tropical habitation. Other studies have related to the control of malaria among children in the plain of Ruzizi and the territory of Uvira, the transmission of trypanosomiasis by Glossina brevipalpis on the River Malagarasi, the use of electrophoretic diagrams in nutrition studies, such as in a case of kwashiorkor, morphometric studies of the lakes of Bulera, Luhondo, Mohasi, Mugesera, Bilala, Sake and Bugwero, in Ruandi, including also plankton studies and the study of the littoral fauna. Therapeutic studies of kwashiorkor, studies of the incidence of goitre in Ruanda, of the sensory physiology of the tsetse, a physico-chemical and hydrobiological study of Lake Gileppe, near Verviers, and of the variation with altitude of the potential gradient of the sun have also been made, and biochemical methods applied to the determination of proteins, protein fractions, lipids and cholesterol of blood.

Intraspecific variations among Hyperolius viridiflavus and $H$. lateralis have been studied in Ruanda and Urundi; Schoutedenella mossooensis sp. n. du Mosso, probably a new race of Hyperolius cinnamomeoventri, a Congo species encountered for the first time in Ruanda in the valley of the Akamyaru, was captured as well as three other species not previously captured in Ruanda-Urundi: Atractaspis bibroni rostrata, Hyperolius oxyrhynchus and Schoutedenella lameerei. An inventory and ecological study were made of some arthropods of the Great Lakes, and a study of the indigenous political organization of the kingdom of Ruanda was completed for presentation as a thesis. An inquiry into the migrations and biology of the fish of a river torrent in the Tanganyika basin, studies of the syncline of Itombwe between Lakes Kivu and Tanganyika and of the frequency of the sickle-cell trait, examination of anthropometric practices in Ruanda-Urundi, the prehistoric industry of the plain of the Lemba, anæmia in states of malnutrition and paludism in mammals and the invertebrate hosts are also noted, as well as the reorganization of the system of demographic inquiry in RuandaUrundi.

\section{HOP PICKING BY MACHINE}

$\mathrm{S}^{\mathrm{r}}$

INCE the Second World War, shortage of labour for picking hops by hand has forced English growers in increasing numbers to turn to the use of picking machines. In 1947 it was estimated that not more than eight machines were in use; the figure had increased to more than a hundred machines in 1954 and a further hundred machines are on order for 1955. These machines are mainly large stationary types which are best suited to the needs of growers of larger acreages. Smaller machines are being produced for the smaller growers, so it is probable that within a few years English hops will be picked mainly by machine.

These developments have been kept under observation by the Department of Hop Research of Wye College, Kent. Each year from 1949 until 1953 inclusive, the Department, with encouragement and financial help from the Agricultural Research Council, has organized surveys of picking machines at work on the farms of commercial growers. The results of these surveys have been published in detail in the annual reports of the Department for the years 1950-53 inclusive. At the request of the Hops Marketing Board, the findings of the surveys have been summarized in an article by $G$. P. Chater and Miss C. L. Jary*.

The main point emerging from the surveys is the importance of intelligent and efficient management ; the best of picking machines will give poor results if badly managed.

The concept of machine picking as a factory process is a valid one. From plant to pocket the hops pass along a production line, and, as in all mechanized industries, good management based on a clear understanding of the process as a whole is essential if a good final sample of dried hops is to be produced.

The chief disadvantage of all picking machines is the amount of breakage they cause to the hop cones. Such breakage makes for difficulties in subsequent cleaning and drying and may lead to wastage of hop material in general and of resins in particular. The subject of resin-loss is a controversial one. An investigation is nearing completion at Wye in which a series of forty-two pairs of pocket samples from the 1954 crop is being examined. Each pair consists of hops of the same variety and from the same farm, one sample of each pair being hand picked and the other machine picked. Preliminary results show that in thirty-five of the forty-two pairs of samples the hand-picked hops appear to have more resin than the machine-picked ones; in the remaining seven pairs the machine-picked hops appear to have a higher resin content than the hand-picked samples.

One of the most important objects of future research on machine picking must be to reduce damage to the cones. In addition to preventing wastage and improving drying performance, such reduction in the breakage of cones would reduce the risk of resin-loss. Future research in England may also have to pay attention to the cleaning of machinepicked hops. In the United States, picking machines have been in general use for some ten years and more than 90 per cent of the crop there is now picked by machine. American growers are now producing by machine-picking large quantities of dried hops with less than 2 per cent by weight of leaf and stem. Data collected in the Wye College surveys suggest that English machine-picked hops have from 3 per cent to 12 per cent of leaf and stem and that hand-picked hops have 3-6 per cent ; such information is too scanty to permit of large generalizations. It is possible, moreover, that the relative eleanness of American machine-picked hops is achieved by tolerating a degree of wastage of broken hops that could not be accepted at present in England. This aspect of machine picking would appear to merit investigation.

In the Wye College surveys the approach was that of the hop grower rather than that of the agricultural engineer. This approach was the only one permitted by the circumstances and has yielded valuable results. It has, however, obvious limitations, and the time has come for research on picking machines, and on the related problem of the drying of machinepicked hops, to be taken up by a team of agricultural engineers.

If research on the machine becomes the responsibility of the agricultural engineer, the growing of * Obtainable from the Secretary, Wye College, Ashford, Kent. $1 s$. 